\title{
Glycemic index lowering effect of different edible coatings in foxtail millet
}

\begin{abstract}
A study was taken up to test the Glycemic Index (GI) of foxtail millet (Setaria Italica). Six healthy subjects between 22-28 years were selected and informed consent was taken from all of them. White bread was used as the standard food. Test foods used were uncoated foxtail millet and coated foxtail millet prepared in the form of rice (millet was cooked only with water). White bread and all the test foods containing $50 \mathrm{~g}$ of carbohydrates each were given to the subjects. The coatings used on the foxtail millet were gum acacia, fenugreek seed paste, curry leaves paste and aloe vera gel. Blood glucose levels were taken at the fasting level and after 30, 60, 90 and 120 minutes of consumption of the white bread and all the test foods. Besides these, in order to test the GI of a mixed meal, seasoned rice (foxtail millet, onion, vegetable oil, groundnut, bengal gram dhal, black gram dhal, mustard seed, cumin seed, green chillies, curry leaves and tomato) was also prepared and given to the same subjects. Results showed that the GI ranges from 28 to 33; with fenugreek seeds coated millet having the lowest GI of 28 followed by curry leaf coated (30), aloe vera coated (31) and gum acacia coated (32) and the uncoated millet having the highest GI of 33. The GI of the mixed meal was 47 . When compared to the uncoated millet, the coated ones had lower GI though the difference was not statistically significant. A negative correlation was observed between GI of coated and uncoated millet and dietary fiber $(\mathrm{r}=-0.85)$ but a positive correlation was there between GI of foxtail millet (coated and uncoated) and starch $(\mathrm{r}=0.95)$. Thus it can be inferred that the uncoated foxtail millet and coated foxtail millets are effective in lowering blood glucose levels.
\end{abstract}

Volume 8 Issue 6 - 2018

\author{
Baphiralang Wahlang, Neena Joshi, Usha \\ Ravindra \\ University of Agricultural Sciences, GKVK, India
}

Correspondence: Baphiralang Wahlang, University of Agricultural Sciences, GKVK, Bengaluru, Karnataka, India, Email wahbephi@gmail.com

Received: October 29, 2018 | Published: November 19, 2018

Keywords: foxtail millet, coatings, glycemic index, subjects

\section{Introduction}

Foxtail millet (Setaria italica) has low glycemic index. ${ }^{1}$ Hypoglycaemic effect is due to the presence of higher levels of complex carbohydrates, resistant starch, slow rising sugars and high fiber content. ${ }^{2}$ Millets also have $\beta$-glucans which are water soluble gums helpful in improving glucose metabolism., ${ }^{3,4}$ Low glycemic index foods have been found to reduce hunger and increase satiety, improve insulin sensitivity and lower blood glucose levels after their consumption. ${ }^{4,5}$ Foxtail millet grain is dehusked before consumption. Dehusking is essential because the outer layers are tough and unedible. This however brings about a loss in its natural antioxidants like phytic acid and polyphenolic compounds because these are mostly present in the outer husk. ${ }^{6-10}$ Dehusked grain has a very short shelf life due to rancidity caused by the exposure of the polyunsaturated fatty acids present in the unpolished grain to atmospheric oxygen. Thus edible coatings can be applied to make up the loss due to dehusking.

An edible coating (EC) is a thin layer of edible substance formed as a covering on a food product having the role of shielding the product from mechanical damage. It also protects the product from physical, chemical and microbiological activities. Proteins, lipids, polysaccharides or a combination of these form the base of such coatings. The added advantage given by edible coatings is that they are natural substances and not chemically manufactured. ${ }^{11}$ Due to edible coatings, changes occur in the colour, texture, sensory attributes, antioxidant and microbial activities and production of ethylene and volatile compounds in fresh and minimally processed foods. ${ }^{12,13}$ These coatings also play a role in food preservation and in stabilization of lipids and lipid containing foods, thus inhibiting the loss of sensory and nutritional quality in food products..$^{14}$ Gum acacia, fenugreek (Trigonella foenum-graecum L) seeds, curry leaf (Murraya koenigii) and aloe vera (Aloe barbadensis) gel are common hypoglycaemic and antioxidant rich ingredients. ${ }^{15-21}$ The edible coatings that have been used in the study are natural and so are considered safe. It is envisaged that coating the foxtail millet with these edible substances may improve the glycemic index (GI) along with its keeping quality, nutritional value and antioxidant activity. However in this paper the effect on GI is only shown.

\section{Materials and methods}

The variety of foxtail millet used for the study was Prasad (SiA 326). The sample was procured from All India Coordinate Research Project on millets, University of Agricultural Sciences (UAS), GKVK, Bangalore.

\section{Edible coatings}

Gum acacia, fenugreek seed, curry leaf and aloe vera were selected as coating material. Curry leaves and aloe vera were taken from plants maintained in Department of Horticulture, University of Agricultural Sciences, Bangalore. Gum acacia was purchased from Qualigens, Division of GlaxoSmithKline pharmaceuticals Ltd., Mumbai, 400030. Fenugreek seed was procured from the local market in Bangalore $2.5 \mathrm{~g}$ gum acacia was dissolved in $25 \mathrm{ml}$ water and then coated onto $100 \mathrm{~g}$ of millet. $10 \mathrm{~g}$ of the gel portion of aloe vera was coated onto $100 \mathrm{~g}$ of millet. Fenugreek paste ( $5 \mathrm{~g}$ seed powder dissolved in $20 \mathrm{ml}$ water) was coated onto 100 gof millet. Curry leaf paste from $5 \mathrm{~g}$ of powder (which was dehydrated by microwave oven) dissolved in $20 \mathrm{ml}$ 
water was coated on $100 \mathrm{~g}$ of millet. The coatings were evenly mixed with the millet manually so that no lumps were formed. After that the coated grains were then dried under shade at room temperature $\left(26^{\circ} \mathrm{C}, \mathrm{RH} 40 \%\right)$. After drying, the grains were stored in high density polyethylene pouches.

\section{Estimation of Insoluble Dietary Fibre (IDF)}

Defatted foods were gelatinized and proteins and starch were removed by enzymatic digestion. The residue was quantitated gravimetrically. ${ }^{22}$

$\mathrm{IDF} \%=\frac{\text { Wt } \text { of the IDF residue }(\mathrm{g}) \quad-\quad\{\text { Protein }(\mathrm{g}) \text { in IDF residue }+\mathrm{Ash}(\mathrm{g}) \text { in IDF residue }\}}{\text { Wt of the sample }(\mathrm{g})} \times 100$

\section{Estimation of Soluble Dietary Fibre (SDF)}

The soluble fibre was estimated in the filtrate obtained after enzymatic digestion of protein and carbohydrates of defatted food. The soluble fibre was precipitated and estimated gravimetrically. ${ }^{22}$

$\mathrm{SDF} \%=\frac{\text { Wt of the SDF residue }(\mathrm{g})-\quad \text { Protein }(\mathrm{g}) \text { in SDF residue }+ \text { Ash }(\mathrm{g}) \text { in SDF residue }\}}{\text { Wt of the sample }(\mathrm{g})} \mathrm{X} 100$

\section{Estimation of total dietary fibre (TDF)}

The total dietary fibre was the sum of the insoluble and soluble dietary fibre. ${ }^{22}$ It was estimated as follows:

Total Dietary Fibre $=$ IDF + SDF values

\section{Estimation of total starch by anthrone method}

The sample is treated with $80 \%$ alcohol to remove sugars and then starch is extracted with perchloric acid. In hot acidic medium starch is hydrolysed to glucose and dehydrated to hydroxymethyl furfural This compound forms a green coloured product with anthrone. ${ }^{23}$ The glucose content in the sample was estimated using the standard graph, and then the value is multiplied by a factor to arrive at the starch content.

Starch content $(\%)=$ Glucose content $(\%) \times 0.9$

\section{Glycemic index test}

The glycemic index is defined as the incremental area under the blood glucose response curve of a $50 \mathrm{~g}$ carbohydrate portion of a test food expressed as a percent of the response to the same amount of carbohydrate from a standard food taken by the same subject. ${ }^{24}$

\section{Study subjects}

Six healthy subjects aged between 22-28years were selected for the study from the University of Agricultural Sciences, GKVK, Bangalore. Informed consent was taken from all the subjects and

\section{Glycemic index of the test food}

IAUC: Incremental Area under Curve

\section{Statistical analysis}

Analysis of variance (F-test) was done. The data was analyzed using the SPSS version 13.0. Significant difference was defined as $p \leq$ 0.05 . Test used for correlation is Pearson.

\section{Results and discussion}

The per cent insoluble dietary fiber (IDF), soluble dietary fiber (SDF) and total dietary fiber (TDF) has been presented in Table 1. Foxtail millet has high dietary fiber content. Different workers have analyzed its dietary fiber content and the values reported were 21.4 per cent and 22.29 per cent, ${ }^{3} 27.00$ and 27.88 per cent, ${ }^{25} 19.11$ per permission to conduct the study was taken from the Chief Medical Officer of the University Dispensary. The subjects were advised not to take any medication and to avoid physical exertion, fasts and feasts during the experimental period. They were also told to finish eating within 10 minutes. The same subjects were recruited for assessing the glycemic index of all samples ensuring a wash out period of one day between the samples.

\section{Standard food and test foods}

The standard food used was white bread. Uncoated foxtail millet and foxtail millet coated with gum acacia, fenugreek seed paste, curry leaves paste and aloe vera gel prepared as rice were tested for their glycemic response on six healthy subjects. Portions of white bread and all the test foods containing $50 \mathrm{~g}$ of carbohydrates each were served. Seasoned rice was also prepared and given to test the GI of a mixed meal. The ingredients used were foxtail millet, onion, vegetable oil, groundnut, bengal gram dhal, black gram dhal, mustard seed, cumin seed, green chillies, curry leaves and tomato.

\section{Blood glucose response}

Blood glucose levels were taken at the fasting level and after $30,60,90$ and 120 minutes of consumption of the white bread and all the test foods. The peripheral blood glucose was obtained using $28 \mathrm{G}$ pricking lancets and the blood glucose in peripheral blood was estimated using in vitro diagnostic kit (XCE 188 -1311) of Abott Diabetes care Inc. Almeda. CA 94502, USA. The glycemic index was calculated using the following formula.

$\frac{\text { IAUC of the test food }}{\text { IAUC of the standard food }} \times 100$

cent, ${ }^{26} 26.92$ per cent ${ }^{27}$ and $8.8,11.8,10.8,8.3$ and 8.2 per cent for decorticated, popped, flaked, roller dried and extruded foxtail millet respectively. ${ }^{28}$ The dissimilarity in the values may be due to the agricultural conditions, varietal differences and processing methods used. Itagi ${ }^{3}$ used spice mixture (fenugreek, coriander seeds, cumin seeds and black pepper) in order to reduce the glycemic index. When they did this it brought about a slight increase in its dietary fiber content. In the present study the dietary fiber content of the foxtail millet was 15.28 per cent and the use of the edible ingredients in the form of coatings brought about a small but significant increase in its dietary fiber content. The order of the increments in dietary fiber contents was fenugreek coated $>$ aloe vera coated $>$ gum acacia coated $>$ curry leaf coated foxtail millet. 
Table I Insoluble dietary fibre, soluble dietary fibre and total dietary fibre content of the uncoated and coated foxtail millet

\begin{tabular}{llll}
\hline Treatments & Insoluble Dietary Fibre & Soluble Dietary Fibre & Total Dietary Fibre \\
\hline Uncoated & 9.99 & 5.29 & 15.28 \\
Gum acacia coated & 10.66 & 6.51 & 17.16 \\
Fenugreek seed coated & 13.18 & 5.37 & 18.54 \\
Curry leaf coated & 10.92 & 5.98 & 16.9 \\
Aloe vera coated & 11.66 & 5.61 & 17.27 \\
F value & $*$ & $*$ & $*$ \\
SEm \pm & 0.1 & 0.19 & 0.22 \\
CD & 0.38 & 0.68 & 0.8 \\
\hline
\end{tabular}

* Significant $(\mathrm{p}<0.05)$

The SDF content of the uncoated foxtail millet was 5.29 per cent. The use of edible ingredients brought about an increase in the SDF content of the millet the order being gum acacia coated $>$ curry leaf coated $>$ aloe vera coated $>$ fenugreek coated millet. The values found out by other workers for SDF content in foxtail millet were 11.56 and 11.91 per cent, ${ }^{25} 11.04$ per cent $^{27}$ and 3.6, 5.0, 4.8, 3.7 and 4.4 per cent for decorticated, popped, flaked, roller dried and extruded foxtail millet respectively. ${ }^{28}$ Differences in the values are due to variation in processing methods used and varieties. IDF content was observed in the range of 9.99 to 13.18 per cent. IDF contents of the coated foxtail millets were higher than the uncoated one. The IDF content was highest in fenugreek coated sample followed by aloe vera coated, curry leaf coated and gum acacia coated. The IDF content reported by different workers were 15.44 and 15.97 per cent, ${ }^{25} 15.88$ per cent ${ }^{27}$ and 5.2, 6.8, 6.0, 4.6 and 3.8 per cent for decorticated, popped, flaked, roller dried and extruded foxtail millet respectively. ${ }^{28}$ Differences are observed between the reported values and the ones in the present study which may be due to the presence of other components like insoluble polysaccharides which could not be easily hydrolyzed by enzymes.

The starch content of the foxtail millet sample was $46.47 \mathrm{~g} / 100 \mathrm{~g}$ (Table 2). There was a reduction in the starch content of the millet with edible coatings the order being fenugreek coated $<$ curry leaf coated $<$ aloe vera coated $<$ gum acacia coated. The decreasing starch content in coated material could be due to the higher total dietary fibre content. The results for the uncoated millet found in the study is on par with those reported by Antony ${ }^{29}$ of 47.3 per cent but lower than those reported by Wankhede ${ }^{30}$ of 56.2 per cent, Bangoura ${ }^{25}$ of 64.12 per cent and Thathola ${ }^{27}$ of 57.57 and 52.44 per cent. The mean blood glucose levels for the test foods in the healthy subjects as compared to that of the standard (white bread) are depicted in Table 3. In the present study, the mean blood glucose levels were significantly lowered in all the test foods thus inferring that uncoated foxtail millet and coated foxtail millets are effective in lowering the blood glucose levels at 30 , 60,90 and 120minutes of ingestion of the test foods. In the present study the coatings effectively reduced blood glucose levels at 30 and 60 minutes. This result is significant because after being secreted from beta cells of Islets of Langerhans, the insulin molecules activity is known to be maximum during these time periods. ${ }^{31}$ Thus it may be inferred that the coatings are effective in controlling the raises in blood glucose levels during the peak insulin activity.

Table 2 Starch content of the uncoated and coated foxtail millet $(\mathrm{g} / \mathrm{/00g})$

\begin{tabular}{ll}
\hline Treatments & Starch \\
\hline Uncoated & 46.47 \\
Gum acacia coated & 43.91 \\
Fenugreek seed coated & 39.27 \\
Curry leaf coated & 42.62 \\
Aloe vera coated & 43.36 \\
F value & $*$ \\
SEm \pm & 0.43 \\
CD & 1.34 \\
\hline
\end{tabular}

* Significant $(p<0.05)$

Table 3 Mean blood glucose levels of the standard and the test foods in healthy subjects ( $\mathrm{mg} / \mathrm{dl}$ )

\begin{tabular}{llllll}
\hline Carbohydrate source & Fasting & $\mathbf{3 0}$ minutes & $\mathbf{6 0}$ minutes & $\mathbf{9 0}$ minutes & $\mathbf{1 2 0}$ minutes \\
\hline White bread & 85.8 & 137.5 & 125.5 & 116.9 & $\mathbf{1 0 2 . 8}$ \\
Uncoated foxtail millet & 86.8 & 121.5 & 93.2 & 88.5 & 80.2 \\
Gum acacia coated foxtail millet & 86.8 & 122.7 & 100.7 & 90.3 & 79.3 \\
Fenugreek seed coated foxtail millet & 86.8 & 119 & 97.5 & 88.5 & 78.8 \\
Curry leaf coated foxtail millet & 87 & 118.7 & 94 & 88 & 79.2 \\
Aloe vera coated foxtail millet & 87.2 & 128.3 & 101 & 89.8 & 79.5 \\
F value & NS & $*$ & $*$ & $*$ & $*$ \\
SEm \pm & 2.91 & 3.85 & 4.33 & 2.14 & 2.56 \\
CD & & 10.66 & 12 & 5.93 & 7.09 \\
\hline
\end{tabular}

*Significant $(p<0.05)$, NS: Non significant 
The Glycemic Index of the different test foods is shown in Table 4. The GI ranges from 28 to 33 ; with fenugreek seeds coated foxtail millet having the lowest GI of 28 followed by curry leaf coated (30), aloe vera coated (31) and gum acacia coated (32) and the uncoated foxtail millet having the highest GI of 33 . When compared to the uncoated millet, the coated ones had lower GI though the difference was not statistically significant. A negative correlation was observed between GI of coated and uncoated foxtail millet and dietary fiber $(\mathrm{r}=-0.85)$ but a positive correlation was there between GI of foxtail millet (coated and uncoated) and starch $(\mathrm{r}=0.95)$. The rate of digestion of foods and their glycemic responses are affected by the presence of dietary fiber, protein, fat, antinutrients, type of carbohydrates, type of food processing and cooking, degree of ripeness and storage. ${ }^{32,33}$ The glycemic responses for different foods are markedly different in diabetic and normal subjects. ${ }^{3}$ According to Thilakavathy ${ }^{34}$ the range of high glycemic index is from 70 or higher, intermediate from 56-69 and low $0-55$. Thus uncoated and coated millets in the study have low GI and can thus be recommended for diabetics.

Table 4 Glycemic Index of the test foods in healthy subjects

\begin{tabular}{ll}
\hline Treatments & GI \\
\hline Uncoated & 33 \\
Gum acacia coated & 32 \\
Fenugreek seeds coated & 28 \\
Curry leaf coated & 30 \\
Aloe vera coated & $3 \mathrm{I}$ \\
F value & $\mathrm{NS}$ \\
SEm \pm & $7.5 \mathrm{I}$ \\
\hline
\end{tabular}

\section{NS: Non significant}

The GI of the fenugreek coated foxtail millet sample had the lowest GI when compared with the other test foods which is due to its higher total dietary fiber content thus protecting starch from enzymatic degradation. The hypoglycaemic effect of dietary fibre could be due to the delaying of starch hydrolysis and glucose absorption and also improvement in glucose utilisation and insulin sensitivity in target tissues. Other workers ${ }^{2,35,36}$ also observed a negative association between dietary fiber and GI of foods. Soluble dietary fibre, present in fenugreek seed, exerts anti-diabetic effects mediated through inhibition of carbohydrate digestion and absorption and enhancement of peripheral insulin action. Galactomannan, present in large amounts in soluble fraction, may also be responsible for its hypoglycaemic and hypocholesterolemic effects. In addition, fenugreek seeds contain an unusual amino acid 4-hydroxyisoleucine, which is known to stimulate insulin secretion through direct action on pancreatic beta cells and also reduce peripheral insulin resistance, thereby improving glucose tolerance. Trigonelline, an alkaloid present in fenugreek seeds is also known to lower blood sugar level and saponin fraction..$^{20,21}$ This seed also has a hypoglycaemic activity due to the presence of alkaloids, flavonoids, salicylate, nicotinic acid and polyphenols. ${ }^{15}$

In India, curry leaf is used as a traditional spice in many food preparations. There is also a practice of using curry leaf in folk medicine for treating different metabolic and infectious diseases. The antioxidant activity of this leaf is due to the presence of carbazole alkaloids-mahanimbine, murrayanol and mahanine. ${ }^{15,18}$ In diabetes mellitus, there is increased in production of reactive oxygen species leading to oxidative stress. Thus antioxidant rich compounds are required to fight back against such complication. Hence it can be concluded that the antioxidant property of this leaf has led to lowering of the blood glucose levels. Tembhurne ${ }^{18}$ have also shown the protective effect of Murraya koenigii (L) leaves extract in streptozotocin induced diabetics rats involving possible antioxidant mechanism. In gum acacia coated foxtail millet, the presence of galactomannan contributes to the lowering of blood glucose which is mainly due to its viscosity. ${ }^{37}$ Viscous fibres may impair mixing of intestinal contents, thereby impair digestion due to limited access of the food to the enzymes. ${ }^{38}$ The antioxidant activity of gum acacia has been shown to be linked with its protein fraction, mainly histidine, tyrosine and lysine, which are amino acid residues generally regarded as antioxidant molecules. ${ }^{16}$

The hypoglycemic effect of aloe vera may be due to presence of polysaccharides and bioactive compounds which increase intestinal transit time, delay gastric emptying and slow glucose absorption. ${ }^{39,40}$ To find out the GI in a mixed meal using a major portion of foxtail millet with the incorporation of onion, vegetable oil, groundnut, bengal gram dhal, black gram dhal, mustard seed, cumin seed, green chillies, curry leaves and tomato was given as a test meal to subjects. The standard food used was white bread. The Glycemic Index of the test meal was 47 which fall under low GI food. ${ }^{34}$ This value is comparable with the one reported by Itagi ${ }^{3}$ of 49.60 who developed a diabetic mix using foxtail millet, wheat semolina, black gram dhal, fenugreek, coriander seeds, cumin seeds and black pepper. However the GI of this test meal is higher when compared to the uncoated and coated foxtail millet, the reason being that the glycemic response to individual foods are lost when they are combined in a mixed meal. ${ }^{32}$ Therefore even though the test meal has other ingredients which are known to be hypoglycaemic, it is important to test each one individually for their GI before testing as a mixed meal. Thus, from the study it can be inferred that the uncoated foxtail millet and the foxtail millet coated with gum acacia, fenugreek seed, curry leaf and aloe vera are effective in lowering blood glucose levels.

\section{Acknowledgement}

The authors thank the Department of Science and Technology, Government of India for providing fund to carry out the study through the Inspire Fellowship and also the Chief Medical Officer, University of Agricultural Sciences, Bangalore and the Project Coordinator, AICRP on Small Millets of the University.

\section{Conflict of interest}

The authors declare that there is no conflict of interest.

\section{References}

1. Hathan BS, Prasanna BL. Optimization of fibre rich gluten-free cookie formulation by response surface methodology. World Academy of Science, Engineering and Technology. 2011;5(12):1077-1086.

2. Singh P, Raghuvanshi RS. Finger millet for food and nutritional security. African J Food Sci. 2012;6(4):77-84.

3. Itagi S, Naik R, Bharati P, et al. Readymade foxtail millet -mix for diabetics. Inter J Sci Nature. 2012;3(1):47-50.

4. Arora S, Srivastava S. Suitability of millet-based food products for diabetics. J Food Sci Technol. 2002;39(4):423-426.

5. Vanithasri J, Kanchana S, Hemalatha G, et al. Role of millets and its importance in new millennium. Inter J Food Sci Technol. 2012; 2(1):3547. 
6. Asharani VT, Jaydeep A, Malleshi NG. Natural antioxidants in edible flours of selected small millets. Inter J Food Properties. 2010;13(1):4150 .

7. Chandrasekara A, Naczk M, Shahidi F. Effect of processing on the antioxidant activity of millet grains. Food Chem. 2012;133(1):1-9.

8. Suma PF, Urooj A. Antioxidant activity of extracts from foxtail millet (Setaria italica). J. Food Sci Technol. 2012;49(4):500-504.

9. Sridevi, Nirmala BY, Basavaraj, et al. Antioxidant contents of whole grain cereals, millets and their milled fractions. J Dairying Foods \& HS. 2011;30(3):191-196.

10. Dykes L, Rooney LW. Sorghum and millet phenols and antioxidants. $J$ Cereal Sci. 2006;44(3):236-251.

11. Ali A, Maqbool M, Ramachandran S, et al. Gum arabic as a novel edible coating for enhancing shelf-life and improving postharvest quality of tomato (Solanum lycopersicum L.) fruit. $J$ Postharvest Bio. 2010;58(1):42-47.

12. Falguera V, Quintero JP, Jimenez A, et al. Edible films and coatings: Structures, active functions and trends in their use. Trends in Food Sci Technol. 2011;22(6):292-303.

13. Del-Valle V, Hernandez-Munoz P, Guarda A, et al. Development of a cactus-mucilage edible coating (Opuntia ficus indica) and its application to extend strawberry (Fragaria ananassa) shelf-life. J Food Chem. 2005;91:751-756.

14. Haq MA, Alam MJ, Hasnain A. Gum Cordia: A novel edible coating to increase shelf life of Chilgoza (Pinus gerardiana). LWT- Food Sci Technol. 2013;50(1):306-311.

15. Devatkal SK, Thorat PR, Manjunatha M, et al. Comparative antioxidant effect of aqueous extracts of curry leaves, fenugreek leaves and butylated hydroxytoluene in raw chicken patties. J. Food Sci Technol. 2012;49(6):781-785.

16. Montenegro MA, Boiero ML, Valle L, et al. Gum Arabic: More than an edible emulsifier. Products and applications of biopolymers. 2012; Chapter 1:1-26.

17. Priya V, Jananie RK, Vijayalakshmi K. Studies on anti-oxidant activity of Trigonella foenum graecum seed using in vitromodels. Inter $J$ Pharmaceutical Sci Res. 2011;2(10):2704-2708.

18. Tembhurne SV, Sakarkar DM. Protective effect of Murraya koenigii (L) leaves extract in streptozotocin induced diabetics rats involving possible antioxidant mechanism. J. Medicinal Plants Res. 2010;4(22):2418-2423.

19. Singh A, Singh AK. Optimization of processing variables for the preparation of herb bread using aloe vera gel. J Food Sci Technol. 2009;46(4):335-338.

20. Gopalpura PB, Jayanthi C, Dubey S. Effect of Trigonella foenumgraecum seeds on the glycemic index of food: A clinical evaluation. Int $J$ Diab Dev Ctries. 2010;27(2):41-45.

21. Bamji MS, Krishnaswamy K, Brahman GNV. Textbook of human nutrition, 2nd edn. Oxford and IBH Publishing Co. Pvt. Ltd, New Delhi; 2003.

22. AOAC International. Official Methods of Analysis, 18th edn. Association of Official Analytical Chemists, Washington, DC; 1995.
23. Sadasivam S, Manickam A. Biochemical methods, 2nd edn. New Age International Ltd Publishers; 1991.

24. FAO/WHO. Carbohydrates in human nutrition. Report of a Joint FAO/ WHO Expert Consultation. FAO Food Nutr Pap. 1998;66:1-140.

25. Bangoura ML, Ming ZH, Nsor-Atindana J, et al. Extraction and fractionation of insoluble fibres from foxtail millet (Setaria italica (L.) P.Beauv). Am J Food Technol. 2011;6(12):1034-1044.

26. Devi PB, Vijayabharathi R, Sathyabama S, et al. Health benefits of finger millet (Eluesine coracana L.) polyphenols and dietary fiber: a review. $J$ Food Technol. 2011;51(6):1021-1040.

27. Thathola A, Srivastava S. Suitability of foxtail millet (Setaria italica) and barnyard millet (Echinochloa frumentacea) for development of low glycemic index biscuits. Mal J Nutr. 2010;16(3):361-368.

28. Ushakumari SR, Latha S, Malleshi NG. The functional properties of popped, flaked, extruded and roller-dried foxtail millet (Setaria italica). Int J Food Sci Technol. 2004;39(9):907-915.

29. Antony U, Sripriya G, Chandra TS. The effects of fermentation on the primary nutrients in foxtail millet (Setaria italica). Food Chem. 1996;56(4):381-384.

30. Wankhede DB, Shehnaj A, Rao MR. Carbohydrate composition of finger millet (Eleusine coracanaj) and foxtail millet (Setaria italica). Qual Plant- Pl Fds Hum Nutr. 1979;28(4):293-303.

31. Survay NS, Ko E, Upadhyay CP, et al. Hypoglycemic effects of fruits and vegetables in hyperglycaemic rats for prevention of type-2 diabetes. Kor J Hort Sc Technol. 2010;28(5):1-7.

32. Jenkins DJA, Wolever TMS, Jenkins AL. Starchy foods and glycemic index. Diabetes Care. 1988;11(2):149-159.

33. Wolever TM. Relationship between dietary fiber content and composition in foods and the glycemic index. Am J Clin Nutr. 1990; 51(1):72-75.

34. Thilakavathy S, Pandeeswari, NK. The glycemic index-A science based diet. Int J Pharm Med and Bio Sc. 2012;1(2):259-265.

35. Torangatti G, Naik RK. Glycemic and lipemic response of composite foods in normal and NIDDM subjects. Int $J$ Diab Dev Ctries. 1999;19:167-171.

36. Thathola A, Srivastava S, Singh G. Effect of foxtail millet (Setaria Italica) supplementation on serum glucose, serum lipids and glycosylated hemoglobin in type 2 diabetics. Diabetologia Croatica. 2010;40(1):2328 .

37. Thakkar R, Kapoor R. Enrichment of rice and finger millet based preparations with gum acacia and their effects on glycemic response in non-insulin dependent diabetic subjects. J Food Sci Technol. 2007;44(2):183-185.

38. Srilakshmi B. Nutrition Science, 3rd edn. New Age International Ltd, Publishers; 2008.

39. Nandal U, Bhardwaj RJ. Aloe vera for human nutrition, health and cosmetic use-A review. Inter Res J Plant Sci. 2012;3(3):38-46.

40. Arora D, Goyal M, Agarwal RP. Efficacy of aloe vera juice consumption on glycemic response in type-2 diabetic patients. J Food Sci Technol. 2009;46(2):160-162. 